九州大学学術情報リポジトリ

Kyushu University Institutional Repository

Farmers' Behaviors, Perceptions and

Determinants of Fertilizer Application in China

: Evidence from Six Eastern Provincial-level Regions

Li, Dongpo

Laboratory of Agricultural and Farm Management, Division of International Agricultural Resource Economics and Business Administration, Department of Agricultural and Resource

Economics, Graduate School of Bioresource and Bioenvironmental Sciences, Kyushu University

Nanseki, Teruaki

Faculty of Agriculture, Kyushu University

Takeuchi, Shigeyoshi

Faculty of Agriculture, Kyushu University

Song, Min

Institute of Agricultural Resources and Regional Planning, Chinese Academy of Agricultural Sciences

他

https://doi.org/10.5109/22078

出版情報: 九州大学大学院農学研究院紀要. 57 (1)，pp.245-254，2012-02. Faculty of Agriculture， Kyushu University

バージョン :

権利関係 : 


\title{
Farmers' Behaviors, Perceptions and Determinants of Fertilizer Application in China: Evidence from Six Eastern Provincial-level Regions
}

\author{
Dongpo LI ${ }^{1}$, Teruaki NANSEKI ${ }^{2}$, Shigeyoshi TAKEUCHI ${ }^{2}$, \\ Min SONG ${ }^{3}$, Tinggui CHEN ${ }^{4}$ and Hui ZHOU ${ }^{5}$
}

\author{
Laboratory of Agricultural and Farm Management, Division of International Agricultural Resource Economics \\ and Business Administration, Department of Agricultural and Resource Economics, \\ Faculty of Agriculture, Kyushu University, Fukuoka 812-8581, Japan \\ (Received October 12, 2011 and accepted November 9, 2011)
}

\begin{abstract}
Based on a survey to 560 household farms in six provincial regions of eastern China, this paper studies farmers' behaviors on the application of fertilizer, including the total amounts, main components of chemical fertilizer and the use of organic fertilizer. Then, it summarizes the farmers' perceptions, ranging from fertilizer choosing, field application, disposal of the used packages and awareness on the possible consequences of over fertilization. Nine indicators are adopted as the predictors, including information on the householders, land-using and planting structure, household income and geographical location. Fertilization Coefficient is formulated to isolate effects of farms' geographical location and planting structure, hence capture farmers' propensities on fertilizing. Through the adoption of binary logistic regression models, this paper identifies significant determinants behind behaviors of the farmers. As to the use of organic fertilizer, although demonstrated as statistically insignificant, possible impacts of chemical fertilization and breeding of livestock and poultry are included as predictors, in addition to the above indicators. Finally, a variety of policy recommendations are put forward, from increasing fertilization efficiency of both chemical and organic fertilizer, to improving farmers' capability and awareness of scientific fertilization.
\end{abstract}

Key words: Behavior, Chinese Household Farm, Determinant, Fertilizer, Perception

\section{INTRODUCTION}

As one of the elemental inputs to agriculture, increasing application of fertilizer has been demonstrated as a key factor in improving China's agricultural productivity over the latest decades (J. Y. Lin, 1992; D. Li, et al., 2011). In 2009, the chemical fertilizer applied to agriculture amounted to 54.04million tons in China, maintained an average annual growth rate of 6.01percent since 1978 (CNSB, 2011). Meanwhile, the excessive use of fertilizer, especially Nitrogen fertilizer, has resulted in serious threats and losses on ecological environment, human health and economic development. In 2008, the fertilizer consumption was $467.98 \mathrm{~kg}$ per hectare of arable land, much larger than the average amount of $134.93 \mathrm{~kg}$ per hectare amongst the 175countries (World Bank, 2011). Field test has revealed the low fertilization efficiency in

Laboratory of Agricultural and Farm Management, Division of International Agricultural Resource Economics and Business Administration, Department of Agricultural and Resource Economics, Graduate School of Bioresource and Bioenvironmental Sciences, Kyushu University; Institute of Rural Economics, Hebei Academy of Social Sciences, Shijiazhuang, Hebei Province, P. R. China

Faculty of Agriculture, Kyushu University

Institute of Agricultural Resources and Regional Planning, Chinese Academy of Agricultural Sciences, P. R. China

${ }^{4}$ College of Economics and Management, Shanghai Ocean University, P. R. China

Laboratory of Agricultural and Farm Management, Division of International Agricultural Resource Economics and Business Administration, Department of Agricultural and Resource Economics, Graduate School of Bioresource and Bioenvironmental Sciences, Kyushu University

* Corresponding author (E-mail: nanseki@agr.kyushu-u.ac.jp)
China: the average Nitrogen absorption efficiency of wheat, corn and rice are 28.3percent, 28.2percent and 26.1percent, far lower than that of 40-60percent in the European and American countries (F. Zhang, et al., 2008). Furthermore, even lower Nitrogen absorption efficiency of only 10percent exists in vegetables, fruits and flowers (W. Zhang, et al., 2004). According to Bulletin of the First National Census on Pollution Sources issued in 2010, the non-point pollution (NPP) of agriculture has become the first source of water contamination in China, while chemical fertilizer applied in crops production constitutes the main source of agricultural NPP. The large volume of fertilizer residues has become a major source of environmental pollution and food safety incidents, thus proper application of fertilizer is drawing unprecedented public concerns. Chinese government has adopted the control of agricultural NPP into the $12^{\text {th }}$ Five-year Plan (2011-2015), with strengthening regulations on fertilizer.

As household farms are the overwhelming managerial units in Chinese agriculture, the understanding of their behaviors and determinants is vital for the combats to agricultural NPP. Although many scholars have conducted concerning studies, there are still a variety of topics need to be researched with further depth. (1) In terms of the survey area, Q. Gong, et al. (2008) surveyed 295 farms from 27villages of 3 prefectures, Hubei Province; H. Han, et al. (2009) surveyed 177 farms in Xinxiang County, Henan Province; C. Yin, et al. (2010) studied the farmers' willingness to reduce amounts of fertilizer used on the crops through sampling 120farms in Nanjing Prefecture, Jiangsu Provinces. If more farms from a larger scope of regions be sampled, the findings 
and conclusions will be more representative to capture their behaviors and important factors of fertilizer application. (2) Some scholars oriented their studies to the fertilizer application on grain crops, including corn and wheat (H. Han, et al., 2009; Z. Zhang, et al., 2011), rice (B. Yan, 2010), etc. However, most of the farms are growing several agricultural products, on which the fertilizer applications are affecting each other, due to limited household budgets, personal preferences, etc. Besides the grain crops, information on cash and other plants should be included, to benefit the overall understanding of farmers' application of fertilizer. (3) In China, farmers have the tradition of using organic fertilizer, behaviors of which may be affected by a variety of factors, including the breeding of livestock and poultry. Thus for a full scenario of fertilization in different farms, it is necessary to obtain information on both the organic fertilizer and significant determinants. (4) Due to the differences in biological species and soil properties, the appropriate amounts of fertilizer are varying amongst different plants and regions. Based on the China Fertilizer Regionalization, Z. Liu, et al. (2008) and Z. Yang, et al. (2011) included the effects of soil conditions in different regions in their analyses of agricultural fertilization. However, most of the studies compared the behaviors and conception on fertilization amongst farms, without the consideration of impacts from the geographical locations and planting structures. To isolate impacts from these factors, more comprehensive indicator systems or specifications are necessary to be introduced. (5) With respect to measurement of farmers' behaviors, some scholars used the willingness of applying organic fertilizer (X. Zheng, 2010), reducing amounts of fertilizer (C. Yin, et al., 2010), while in some other studies, the behaviors are represented by amount of Nitrogen fertilizer (Q. Gong, et al., 2008), willingness of adopting soil-testing technologies (H. Gao, et al., 2011), etc. However, the physical amount of chemical fertilizer, with the consideration of geographical locations and planting structure, is indispensible to analyze farmers' behaviors and conceptions. Furthermore, the integrated analyses on the deter- minants of farmers' application of organic fertilizer, their perceptions and requirements, etc., will be much beneficial for policy recommending.

Therefore, based on the survey to 560household farms of eastern China's 6 provincial-level regions, this study defines farmers' behaviors including total amount of chemical fertilizer, use of organic fertilizer. All the major agricultural products are surveyed and analyzed, including wheat, corn, rice, cotton, fruiters, vegetables, oilseed and peanut. The perceptions investigated cover a variety of concepts from choosing the fertilizer, field application to the possible consequences of over fertilization and disposal of the used packages. To explore significant determinants behind the behaviors, both quantitative and dummy indicators are used to represent predictor and response variables, through the application of binary logistic regression models. The remainder of the paper is organized as follows: the next section briefly describes the field survey and the basic statistical summaries; Sections 3 and 4 analyze determinants on farmers' behaviors towards fertilizer application; in Section 5, conclusions and policy recommendations are presented, followed by open research topics.

\section{THE FIELD SURVEY}

\section{Sample and method}

To understand the present situation and farmers' perceptions on agricultural pollution, we designed the survey with questionnaire-based personal interviews to collect first-hand data as used in many previous studies (e.g., Q. Gong, et al., 2010; H. Gao, et al., 2011). In the first section, our questionnaire contains basic characteristics of each household farm, including demographic information of family members, annual incomes, scale and planting structure of farmland, production and marketing of aro-products, etc. In the second section of the questionnaire, we enquire the disposal of life garbage, including the wasted glasses, plastics, paper and clothes, kitchen and manure garbage, etc. In succession, farmers' selection and application of fertilizer, pesticides and

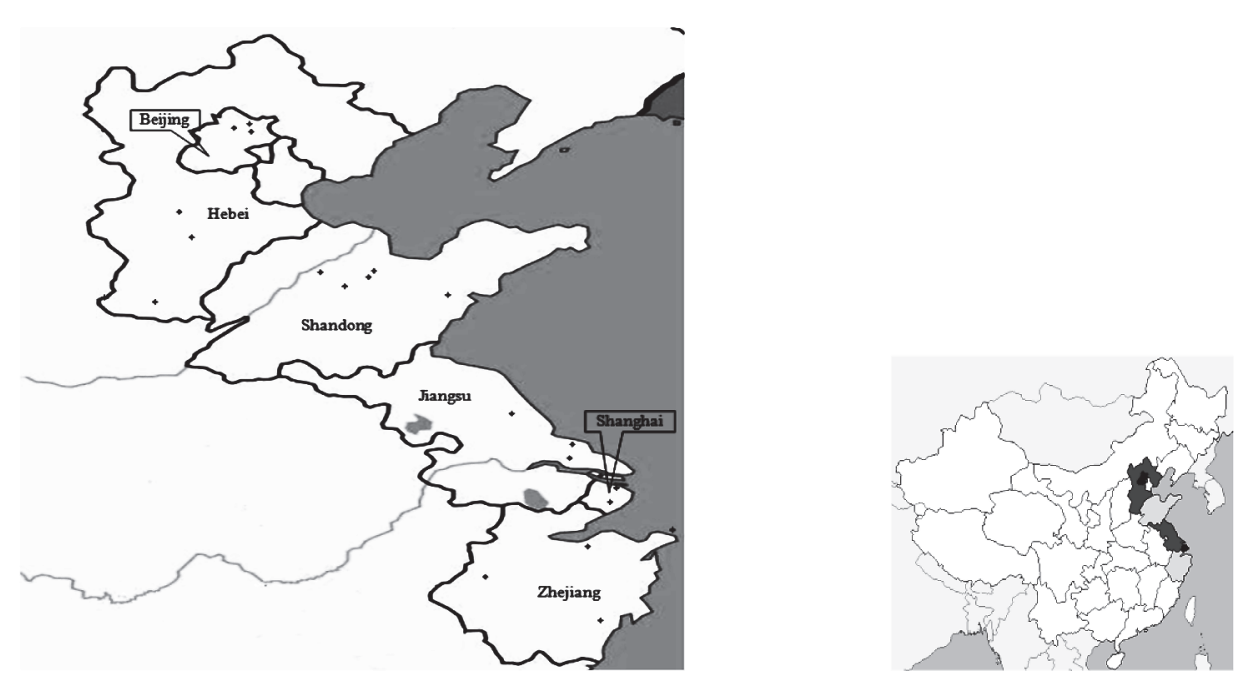

Fig. 1. Location of the sampled areas. 
veterinary drugs are enquired. In the final section, we collected farmers' perceptions on the major sources, routes, responsible parties and countermeasures of agricultural pollution, information and recognition on safe agricultural products. Simultaneously, we designed another questionnaire to capture the general profile of each village, including the demographic information, agricultural production, environmental condition and rural public services, through interviewing the local officials.

In January to March, 2011, we surveyed 560 household farms in 21 villages of eastern China's 6 provinciallevel regions, including Beijing, Hebei, Shandong, Shanghai, Jiangsu and Zhejiang (Fig. 1). The sampled area covers 3 major gains-growing provincial-level regions $^{1}$, and rural regions affiliating to the top two metropolises in China. The former three regions represent the northern mode of Chinese agricultural production in the Yellow River Basin, while the latter three demonstrate characteristics of agricultural production in south China' Yangtze River Basin. Viewing from the topographic types, farms locating in plain, hills and mountainous regions, villages of inlands, seaside and adjoining the metropolises are sampled. In addition to the staple grains crops of wheat, rice and corn, the other major agricultural products, including cotton, vegetables, fruiters, oil crops, etc, and the main livestock, poultry, aquaculture products are being grown and bred in the sampled farms.

\section{Theoretical model}

Drawing upon the rural household models of W. E. Huffman (2001), farmers are assumed to make consumption, production and labor supply decisions by maximizing utility from a home-produced good $Y_{1}$ and leisure $L$ :

$$
U=U\left(Y_{1}, L\right)
$$

subjecting to technology constraints from the production function (Eq. 1-1), human time constraints (Eq. 1-2), and cash income constraints (Eq. 1-3):

$$
\begin{aligned}
& F\left(Y_{1}, Y_{2}, Y_{3}, H, X, A, E\right)=0, \quad Y_{3} \geq 0, X \geq 0 \\
& T=L+H+H_{m}, \quad H_{m} \geq 0 \\
& I=P_{2} Y_{2}+P_{3} Y_{3}+W_{m} H_{m}+V=W_{X} X
\end{aligned}
$$

where $Y_{2}$ and $Y_{3}$ are outputs produced for sale, the market prices of which are $P_{2}$ and $P_{3}$, respectively; total available time per production circle $T$ is allocated among leisure $L$, farm-household work $H$, and off-farm wage work $H_{m}$ with the market wage rate of $W_{m} ; X$ represents purchased variable inputs, with the price vector of $W_{X} ; A$ is technology and agro-climatic conditions; $E$ is an education index of household decision makers; within the cash income of $I, V$ is the household nonfarm-nonlabor income net of any fixed costs associated with farmhousehold production.

To analyze farmers' application of fertilizer $\left(F_{f}\right)$, production decision on a certain variable input $(X)$, four types of variables are included to depict major constraints of household farms in our model:

$$
F_{f}=F(H R, L C, H I, G L)
$$

As household is the most important member in decisionmaking, the category of human resources (HR) consists of variables on age, gender and education level $(E)$ of the households. As the production function Eq. 1-1 permits adopting new inputs (W. E. Huffman, 2001) and land in the basic means in agro-production, two variables on land cultivation $(L C)$ are adopted. In the variables on household incomes $(H I)$, total cash income constraint $(I)$ is represented by annual cash incomes, while offfarm wage work $H_{m}$ is described with the ratio of migrant incomes. Finally, as geographic location $(G L)$ affects the technology and agro-climatic conditions $(A)$, market wage of the off-farm work $\left(W_{m}\right)$ and prices of the inputs

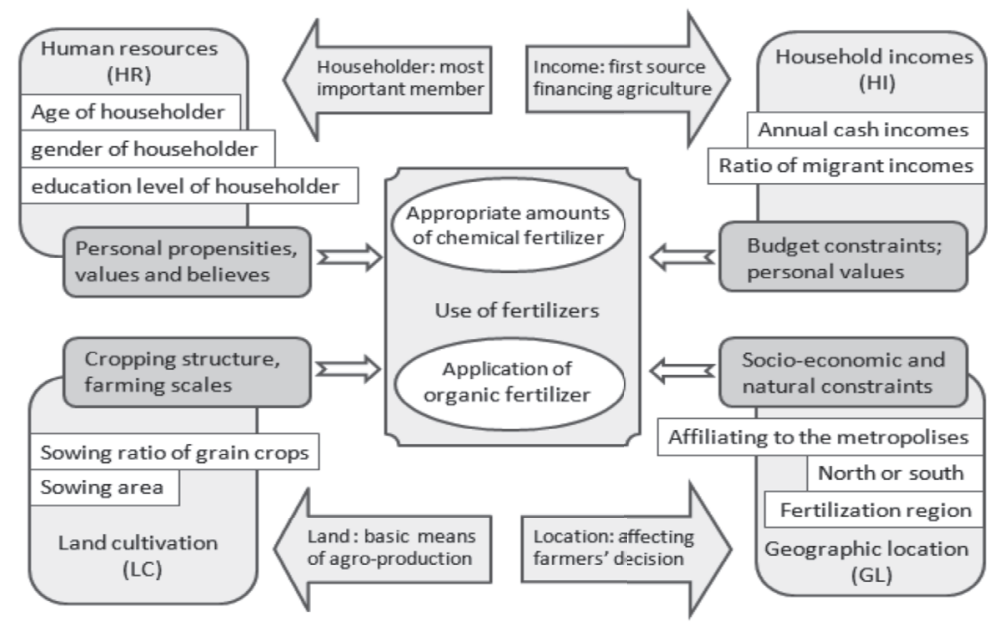

Fig. 2. Mechanism of modeling farmers' use of fertilizer.

The 13 major gains-growing provincial-level regions include Liaoning, Jilin, Heilongjiang, Inner Mongolia, Hebei, Henan, Hubei, Hunan, Shandong, Jiangsu, Anhui, Jiangxi and Sichuan. 
$\left(W_{X}\right)$, three variables are included to show farms' affiliation to the metropolises, the north or south, and location in the National Fertilization Regionalization. Variables in each type and mechanism of modeling farmers' use of fertilizer are shown in Fig. 2. In addition, impacts of planting structure will be analyzed later, through the specification of Fertilization Coefficient as Eq. 3.

\section{Demographic characteristics}

In this study, only farms answered as used fertilizer in 2010 are included, thus the sample consists of 294 valid responses from this survey. Based on the theoretical model specified above, we include 10indicators to represent the demographic characteristics of each farm (Table 1). Simultaneously, these indicators will be used as candidate determinants to interpret farmers' behaviors on fertilizer application.

(1) Considering the importance of householders in making productive decisions within household farms, many studies included concerning variables as determinants in the analysis of safe agricultural production. In this study, we include three variables to describe attributes of the householders, i.e., human resources (HR), as gender (Q. Gong, et al., 2010), age (H. Gao, et al., 2011) and education level (edu, H. Han, et al., 2009). (2) In agrarian societies, land is not only the main means for generating livelihood, but often also for accumulating wealth and transferring it between generations ( $\mathrm{K}$. Deininger, et al., 2001). Thus two continuous variables on land cultivation $(L C)$ are introduced: the sowing area of total agricultural products (scale), rather than total area of farmland is adopted with the consideration of multiple cropping (H. Wang, et al., 2004); sowing ratio of grain crops (grainr) is included to identify the effects of land use structure. (3) Meanwhile, another two variables are introduced to measure impacts of discrepancies in household income $(H I)$ : total annual cash income (income) affects household budgets and thus inputs to agriculture, including the purchase of fertilizer (H. Han, et al., 2009; H. Gao, et al., 2011); ratio of income from migrant job (mir) shows the main sourcing structure of household income, which affects the relative importance of agriculture and the corresponding inputs as well $(\mathrm{H}$. Dai, 2010). (4) To model the influence of geographic location $(G L)$ on farmers' application of fertilizer (J. Ma, 2006), two dichotomous dummy variables are included with north (north or south of China) equal to 1 if a farm is from Beijing, Hebei or Shandong, and metro (metropolises or not) coded as 0 if a farm affiliates to neither Beijing nor Shanghai. The statistical summary of each variable is shown in Table 1. Finally, according to the China National Fertilization Regionalization ${ }^{2}$ (Z. Liu, et al., 2008; Z. Yang, et al., 2011), the sampled areas cover four sub-regions as shown in the statistics following the characteristic variable of fregion.

\section{Behaviors on fertilizer application}

To capture the major behaviors of chemical fertilizer application in a farm, in addition to an aggregate amount, quantities of Nitrogen, Phosphate, Potash and Compound fertilizers used in each agro-product are included. In the sampled farms, the Nitrogen fertilizers mainly include Carbamide, Ammonium bicarbonate, etc; the major Phosphate fertilizer used is Calcium superphosphate; Potash fertilizers are consist of Potassium sulfate, etc. Amongst the three types of macro-element fertilizers,

Table 1. Demographic characteristics of the sampled farms applied fertilizer

\begin{tabular}{|c|c|c|c|c|c|c|c|c|}
\hline Characteristic & Type $^{\text {a }}$ & Unit & $\mathrm{N}$ & Mean & Min & $\operatorname{Max}$ & Std. D. & C. V. \\
\hline Age of householder (age) & $\mathrm{HR}$ & year & 288 & 50.368 & 26.000 & 85.000 & 10.708 & 0.213 \\
\hline Sowing area (scale) & $\mathrm{LC}$ & $m u^{\mathrm{b}}$ & 294 & 5.341 & 0.100 & 38.000 & 5.163 & 0.967 \\
\hline Ratio of grains sowing scale (grainr) & $\mathrm{LC}$ & $\%$ & 289 & 36.845 & 0.000 & 100.000 & 36.702 & 0.996 \\
\hline Ratio of migrant income $(\mathrm{mir})^{\mathrm{c}}$ & $\mathrm{HI}$ & $\%$ & 281 & 35.362 & 0.000 & 100.000 & 41.297 & 1.168 \\
\hline Gender of farm head (gender) & HR & dummy & 288 & \multicolumn{5}{|c|}{$1=$ male $\left(275^{\mathrm{d}}\right) ; 0=$ female $(13)$} \\
\hline Education level of farm head (edu) & HR & dummy & 282 & \multicolumn{5}{|c|}{$\begin{array}{l}1=\text { illiteracy }(12) ; 2=\text { primary }(71) ; 3=\text { middle }(149) ; 4=\text { high }(42) ; \\
5=\text { advanced }(8)\end{array}$} \\
\hline Total cash income in 2010 (income) & HI & dummy & 291 & \multicolumn{5}{|c|}{$\begin{array}{l}1=\text { under } 10000 \text { yuan }(42) ; 2=10000-30000 \text { yuan }(105) ; 3=30000- \\
50000 \text { yuan }(88) ; 4=\text { over } 50000 \text { yuan }(56)\end{array}$} \\
\hline North or south of China (north) & GL & dummy & 294 & \multicolumn{5}{|c|}{$1=$ north $(141) ; 0=$ south $(153)$} \\
\hline Metropolises or not (metro) & GL & dummy & 294 & \multicolumn{5}{|c|}{$1=$ Beijing or Shanghai $(74) ; 0=$ other regions $(220)$} \\
\hline Fertilization region (fregion) & GL & dummy & 294 & \multicolumn{5}{|c|}{$\begin{array}{l}\text { 1=Yanshan-Taihang mountainous areas (33); } 2=\text { Yellow-Huaihe-Haihe } \\
\text { Plain (82); 3=Yangtze River plain (106); 4=Foothill areas South of } \\
\text { Yangtze River (73) }\end{array}$} \\
\hline
\end{tabular}

Note: ${ }^{a}$ referring to the four types of variables shown in Fig. $2{ }^{\text {b }}$ as a main unit of land measurement in China, $1 \mathrm{mu}^{2} 666.67 \mathrm{~m}^{2}$;

${ }^{\mathrm{c}}$ the income sources contain migrant jobs and sales of agricultural products; ${ }^{\mathrm{d}}$ the bracketed numerals denote counts of farms.

Source: field survey by the authors

\footnotetext{
2 The China National Fertilization Regionalization is drafted by Soil and Fertilizer Institute, Chinese Academy of Agricultural Sciences. According to the soil condition and fertilization characteristics, this national planning divides farmland of China into 31 sub-divisions within 8 divisions.
} 
Table 2. Application of fertilizer in the sampled farms

\begin{tabular}{|c|c|c|c|c|c|c|c|}
\hline & Unit & $\mathrm{N}$ & Mean & Min & $\operatorname{Max}$ & Std. D. & C. V. \\
\hline Chemical fertilizer & $\mathrm{kg} / \mathrm{mu}$ & 294 & 58.489 & 8.890 & 285.710 & 45.609 & 0.780 \\
\hline Nitrogen & $\mathrm{kg} / \mathrm{mu}$ & 278 & 34.589 & 2.140 & 285.710 & 34.276 & 0.991 \\
\hline Phosphate & $\mathrm{kg} / \mathrm{mu}$ & 12 & 29.748 & 12.820 & 85.710 & 20.664 & 0.695 \\
\hline Potash & $\mathrm{kg} / \mathrm{mu}$ & 4 & 132.500 & 10.000 & 200.000 & 89.954 & 0.679 \\
\hline Compound & $\mathrm{kg} / \mathrm{mu}$ & 194 & 36.714 & 4.440 & 200.000 & 28.065 & 0.764 \\
\hline Organic fertilizer used in total farms & dummy & 300 & \multicolumn{5}{|c|}{$1=$ used $(206) ; 0=$ unused (94) } \\
\hline Farms used organic and chemical fertilizer & dummy & 224 & \multicolumn{5}{|c|}{$1=$ used (137); $0=$ unused (87) } \\
\hline
\end{tabular}

Note: the bracketed numerals denote counts of farms.

Source: field survey by the authors

Table 3. Application of fertilizer in each agricultural plant

\begin{tabular}{|c|c|c|c|c|c|c|c|c|}
\hline & \multicolumn{7}{|c|}{ Application of chemical fertilizer } & \multirow{2}{*}{$\begin{array}{c}\text { Farms used organic } \\
\text { fertilizer }\end{array}$} \\
\hline & Unit & $\mathrm{N}$ & Mean & Min & $\operatorname{Max}$ & Std. D. & C. V. & \\
\hline Wheat & $\mathrm{kg} / \mathrm{mu}$ & 120 & 63.928 & 2.330 & 333.330 & 40.107 & 0.627 & 50 \\
\hline Corn & $\mathrm{kg} / \mathrm{mu}$ & 120 & 51.159 & 8.330 & 175.000 & 34.749 & 0.679 & 50 \\
\hline Rice & $\mathrm{kg} / \mathrm{mu}$ & 61 & 46.505 & 6.670 & 220.000 & 35.997 & 0.774 & 30 \\
\hline Cotton & $\mathrm{kg} / \mathrm{mu}$ & 32 & 76.189 & 5.000 & 266.670 & 64.482 & 0.846 & 21 \\
\hline Fruiter & $\mathrm{kg} / \mathrm{mu}$ & 9 & 104.153 & 50.000 & 285.710 & 77.292 & 0.742 & 26 \\
\hline Vegetable & $\mathrm{kg} / \mathrm{mu}$ & 51 & 120.415 & 10.000 & 400.000 & 101.775 & 0.845 & 72 \\
\hline Oilseed & $\mathrm{kg} / \mathrm{mu}$ & 41 & 82.603 & 10.670 & 190.000 & 35.687 & 0.432 & 18 \\
\hline Peanut & $\mathrm{kg} / \mathrm{mu}$ & 25 & 62.799 & 6.000 & 140.000 & 33.240 & 0.529 & 5 \\
\hline
\end{tabular}

Source: field survey by the authors

Nitrogen fertilizers are most widely used by 278 (94.56 percent) farms, while Potash fertilizers are used only with 4 (1.36percent) farms. Although many compound fertilizers contain all the macro elements, the general fertilizing trend of rich Nitrogenous and poor Potash nutrients (Z. Liu, et al., 2008; Q. Gong, et al., 2010) is testified from the survey. Meanwhile, the application of organic fertilizer (mainly including manure and compost) is represented in terms of the counts of farms amongst both the total sample and those who used chemical fertilizer simultaneously (Table 2).

The agricultural products we surveyed include wheat, corn, rice, cotton, fruits, vegetables, oilseed, peanut, and the amount of fertilizer per $m u$ used on each product is shown in Table 3. The average fertilizer used in the three main grain crops of wheat, corn and rice is $55.31 \mathrm{~kg}$ per $m u$, which is much less than that of the other products as $91.60 \mathrm{~kg}$ per mu. Within the three main grain crops, wheat is applied with the largest amounts of fertilizer, while vegetable is mostly fertilized amongst all the other categories of agricultural plants. As to the organic fertilizer, it is much widely used in the three main grain crops than in the other agricultural plants.

\section{Perceptions on fertilizer application}

Within the questionnaire, 4 questions are concerning farmers' perceptions on fertilizer application, from choosing, applying and determining the amounts of chemical fertilizer, to the consequences of over fertilization.
Moreover, as most of the fertilizer bags are made from PVC, containing a variety of toxic cancer-causing substances, long-term storage of food is easy to bring about damp mildew and produce a strong carcinogen of aflatoxin (W. Han, 2005). Thus the improper disposal of fertilizer containers may endanger environmental safety and human health, farmers' disposal of the used fertilizer packages is enquired simultaneously. For each question, the number of valid responses, counts and percents of responses to each choice are shown in Table 4.

For most of the farmers, productive effects are the first determining factors in choosing and using fertilizer, less attention is paid upon the environmental effects and sprayers' health. When determine the mounts of fertilizer, more than 50 percent farmers are answered as following package instructions, while some one third of them are relying on their own experiences. In terms to the disposal of used fertilizer packages, almost 60 percent farmers answered as rinsing and reusing, thus pose threats to the environment and human health. In many rural areas, farmers are storing their grains and other food stuffs in the used fertilizer bags, hence make their food in high risk of being contaminated. Some farmers even rinse the used fertilizer bags in rivers, lakes, etc, hence constituting public water contaminations (J. Zhang, et al., 2007). On the possible consequences of over fertilization, as a multiple-choice question, farms chose soil compaction account for an overwhelming ratio of 68.94percent, following by another choice of crop lodging with 45.78per- 
Table 4. Perceptions concerning fertilizer application

\begin{tabular}{|c|c|c|c|c|c|}
\hline Price & Productive effects & The sellers & Peer practices & Follow-up services & Environmental effect \\
\hline $103(18.86 \%)$ & $380(69.60 \%)$ & $16(2.93 \%)$ & $31(5.68 \%)$ & $1(0.18 \%)$ & $15(2.75 \%)$ \\
\hline \multicolumn{6}{|c|}{ 2. Determinants of using fertilizer (Single-choice with 546 valid responses) } \\
\hline Costs & Productive effect & Environmental effect & Sprayers' health & \multicolumn{2}{|c|}{ Quality of agro-product } \\
\hline $120(21.98 \%)$ & $343(62.82 \%)$ & $13(2.38 \%)$ & $7(1.28 \%)$ & \multicolumn{2}{|l|}{$63(11.54 \%)$} \\
\hline \multicolumn{6}{|c|}{ 3. Determinants of fertilizing amounts (Single-choice with 546 valid responses) } \\
\hline Container instructions & Private experience & \multicolumn{2}{|c|}{ Instruction from the extension staff } & \multicolumn{2}{|l|}{ Peer practices } \\
\hline $278(50.92 \%)$ & $191(34.98 \%)$ & \multicolumn{2}{|l|}{$42(7.69 \%)$} & \multicolumn{2}{|l|}{$35(6.41 \%)$} \\
\hline \multicolumn{6}{|c|}{ 4. Disposal of the fertilizer packages (Single-choice with 555 valid responses) } \\
\hline Rinsing and recycling & Burning up & Littering & Collective recycling & \multicolumn{2}{|l|}{ Others } \\
\hline $326(58.74 \%)$ & $33(5.95 \%)$ & $57(10.27 \%)$ & $133(23.96 \%)$ & \multicolumn{2}{|l|}{$6(1.08 \%)$} \\
\hline \multicolumn{6}{|c|}{ 5. Consequences from over fertilization (Multiple-choice with 557 valid responses) } \\
\hline Crop lodging & Soil compaction & Water contamination & Increasing crop yields & Unknown & Others \\
\hline $255(45.78 \%)$ & $384(68.94 \%)$ & $148(26.57 \%)$ & $85(12.56 \%)$ & $39(7.00 \%)$ & $17(3.05 \%)$ \\
\hline
\end{tabular}

Note: numerals are the counts of valid responses, and the bracketed numbers are the corresponding percents of responses. Source: field survey by the authors

cent. As to water contamination, it is chosen by only less than one third of the respondents. Thus the proper and traditional perceptions are coexisting amongst the farmers, as applying fertilizer by package instructions, concerning on possible soil compaction due to over fertilization, while rinsing and reusing the packages for foodstorage, etc.

\section{ANALYSIS ON THE BEHAVIOR DETERMINANTS}

\section{Calculating the Fertilization Coefficient}

As aforementioned, the application of fertilizer is mainly affected by three factors: soil properties represented by the geographical location in the National Fertilization Regionalization, agricultural planting structure and farmers' propensities. This study aims to identify the discrepancies amongst farmers in terms of their propensities and thus behaviors on fertilizer application. Hence for further analysis, it is necessary to insulate impacts of the former two factors. In this survey, average amounts of fertilizer applied per $m u$ in each ago-product are varying amongst different areas in the National Fertilization Regionalization (Table 5).

To show the pure effect of farmers' propensities on determining amounts of chemical fertilizer, an indicator of $F C$ (Fertilization Coefficient) for the i-th farm is formulated as:

$$
F C_{i}=\sum_{j=1}^{8}\left[\frac{s_{i j}}{s_{i}} \cdot \frac{f_{i j}}{f_{\overline{k j}}}\right] \quad(i=1, \cdots, 294 ; k=1, \cdots, 4)
$$

where $s_{i j}$ is the sowing scale of the $j$-th agricultural product in the $i$-th farm; $s_{i}$ is the total sowing scale of agricultural plants in the $i$-th farm; $f_{i j}$ is the fertilizer applied per $m u$ to the $j$-th agricultural product in the $i$-th farm; $f_{\overline{k j}}$ is the average amount of fertilizer applied per $m u$ to the $j$-th agricultural product in the $k$-th region.

The summary statistics of the FCs for the 294 valid responses are shown in Table 6. To differentiate farmers' behaviors of fertilization driven by their propensities, they are divided into three groups in terms of their FCs, and the summary statistics for each group are provided in the same table. Group II embraces FCs fluctuating within 50percent around 1, which represents the moderate amount of fertilizer determined by certain location and planting structure. Meanwhile, farms falling into the Group I and III indicate propensities of applying fertilizer with 50 percent under and over the moderate amounts, respectively. Statistics in this table show that Group II includes 180 farms (61.22percent) with least coefficient of variance than the other two groups.

\section{On the total amounts of fertilizer}

To model the factors significant for the $F C$ of a farm falling to any of the Groups above, the dependent varia-

Table 5. Average amounts of fertilizer applied to each ago-product in different regions (Unit: $\mathrm{kg} / \mathrm{mu}$ )

\begin{tabular}{|c|c|c|c|c|c|c|c|c|}
\hline Sub-division region & Wheat & Corn & Rice & Cotton & Fruiter & Vegetable & Oilseed & Peanut \\
\hline Yanshan and Taihang mountainous areas & & 40.355 & & & 285.710 & & & \\
\hline Yellow river-Huaihe river-Haihe river Plain & 64.975 & 55.229 & & 104.729 & 118.890 & 157.097 & & 51.528 \\
\hline Yangtze River Plain & 60.485 & 53.274 & 54.526 & 58.5525 & & 84.841 & 98.844 & 71.655 \\
\hline Foothill Areas South of Yangtze River & & & 41.302 & 17.500 & 59.000 & 68.75 & 43.353 & \\
\hline
\end{tabular}

Source: field survey by the authors 
ble is a dichotomous indicator being coded 1 if belonging to a certain group and 0 if not. As the OLS models are inappropriate for the discrete and limited dependent variables (Jack J., et al., 1997), a Binary Logit Regression model is adopted and formulated as (H. R. Seddighi, et al., 2000):

$$
\log \left[\frac{P\left(Y_{1}\right)}{P\left(Y_{0}\right)}\right]=\beta_{0}+\sum_{i=1}^{9} \beta_{i} x_{i}+\varepsilon
$$

where $P\left(Y_{1}\right)$ denotes the odds of $F C$ belonging to a certain group, while $P\left(Y_{0}\right)$ represents being in other groups; $x_{1}, x_{2}, \ldots, x_{9}$ are the variables except for fregion in Table $1 ; \beta_{0}$ and $\beta_{i}$ are coefficients to be estimated; $\varepsilon$ is the random error.

Estimation of the model is carried out through application of the Binary Logistic Regression procedure in SPSS 13.0. Backward approach is adopted to remove the statistically insignificant variables $(p$-value $>$ _ 0.1$)$, from the initial model with all the candidate determinants as independent variables. The final model selected includes predictors embracing $p$-value less than 0.01 (Table 7 ). The column of B estimates log-odds coefficients of $\beta_{i}$ in $E q$. 4, for predicting the dependent variable from the independent variables. The last column lists the exponentiation of $\mathrm{B}$, the ratio of $P\left(Y_{1}\right)$ and $P\left(Y_{0}\right)$, thus be called odds ratios simultaneously. In this case, an odds ratio over 1 denotes that the farm is more probably to fall into the group, while an odds ratio less than 1 implies that the farm is easier to falling out of the group (Bruin
J., 2006).

The results show that, (1) Sowing area (scale) is an essential factor occurs in all the three groups, as negative within both I and III, while positive in Group II. It reveals the existence of scale economy in terms of fertilizer application in the sampled farms, thus the increase of managerial scale is favorable for appropriate fertilization (Z. Yang, et al., 2011). (2) As another significant determinant, total annual income is beneficial for the probability of using fewer amounts of fertilizer (J. Ma, 2006). In this survey, apparent positive relationship exists between annual income and non-agricultural ratios. Within the farms included in this model, no migrant income occurred in the farms with annual cash income less than 10000yuan, while this ratio in the other three income levels of Table 1 are 26.71percent, 51.36percent and 55.54percent, respectively. The more non-agricultural income usually result in less farming time and attention in agricultural yields, thus the application of fertilizer may be decreased. (3) Meanwhile, the negative effect from income ratio of migrant job (mir). Due to the instability and high expenditure of living away from homeland, most of the migrant farmers have to leave their families at home and engage in agriculture. As most of the left family members are women, children, and the elderly, they are prone to improve agricultural productivity through chemical fertilizer. The negative effect of mir in Group I may reveals that the more they get from migrant jobs, the more they will be afford to use

Table 6. Summary statistics of FC in different groups

\begin{tabular}{|c|c|c|c|c|c|c|c|}
\hline Group & Range & $\mathrm{N}$ & Mean & Min & $\operatorname{Max}$ & Std. D. & C. V. \\
\hline I & $(0,0.50)$ & 84 & 0.310 & 0.080 & 0.496 & 0.107 & 0.343 \\
\hline II & {$[0.50,1.5)$} & 180 & 0.949 & 0.500 & 1.486 & 0.252 & 0.266 \\
\hline III & {$[1.5,+\infty)$} & 30 & 2.133 & 1.514 & 3.804 & 0.588 & 0.276 \\
\hline Total & & 294 & 0.887 & 0.080 & 3.804 & 0.577 & 0.650 \\
\hline
\end{tabular}

Source: field survey by the authors

Table 7. Binary logistic regression on FC of different groups

\begin{tabular}{|c|c|c|c|c|c|c|c|}
\hline Group & Variable & $\mathrm{B}$ & S. E. & Wald & df & Sig. & odds ratio \\
\hline \multirow{5}{*}{ I } & Age of farm head (age) & $0.020^{*}$ & 0.012 & 2.931 & 1 & 0.087 & 1.020 \\
\hline & Total cash income in 2010 (income) & $0.560 * * *$ & 0.161 & 12.050 & 1 & 0.001 & 1.751 \\
\hline & Sowing area (scale) & $-0.087 * * *$ & 0.032 & 7.275 & 1 & 0.007 & 0.917 \\
\hline & Sowing ratio of grain crops (grainr) & $0.773^{* *}$ & 0.384 & 4.054 & 1 & 0.044 & 2.166 \\
\hline & Ratio of migrant income ( $m i r)$ & $-0.009 * *$ & 0.004 & 6.109 & 1 & 0.013 & 0.991 \\
\hline \multirow{3}{*}{ II } & Total cash income in 2010 (income) & $-0.444^{* * *}$ & 0.144 & 9.423 & 1 & 0.002 & 0.642 \\
\hline & Sowing area (scale) & $0.098 * * *$ & 0.030 & 10.788 & 1 & 0.001 & 1.102 \\
\hline & Ratio of migrant income ( $\mathrm{mir}$ ) & $0.010 * * *$ & 0.003 & 7.672 & 1 & 0.006 & 1.010 \\
\hline III & Sowing area (scale) & $-0.115^{* *}$ & 0.060 & 3.741 & 1 & 0.053 & 0.891 \\
\hline
\end{tabular}

Omnibus tests of coefficients for model I: Chi-square (5)=23.941, Sig. $=0.000 * * *$

Omnibus tests of coefficients for model II: Chi-square $(1)=5.002$, Sig. $=0.025^{* *}$

Omnibus tests of coefficients for model III: Chi-square $(3)=25.191$, Sig. $=0.000 * * *$

Note: *** and **represents statistical significance in the level of $1 \%$ and $5 \%$, respectively

Software: SPSS 13.0 
fertilizer (Q. Gong, et al., 2010). Meanwhile, due to the lack of prime labors, most of them are not over-fertilization, thus being positive in Group II. (4) The positive effect of age in Group I reveals that farms headed by the elderly are easier to fertilize less than the average amounts. It may be interpreted as due to limitation of physical power, disposable income, etc. (5) As analyzed above, the three types of staple grain crops are supplied with less fertilizer than the other agricultural products. Therefore, their sowing ratios (grainr) go positively in Group I hence negatively with the total amounts of fertilizer.

\section{On the application of organic fertilizer}

With the same Binary Logistic Regression procedure in SPSS 13.0, we measure significant factors for the application of organic fertilizer in the sampled farms. Besides the aforementioned 9 variables, we add three variables into the candidate determinants: amount of chemical fertilizer (fert), quantity of livestock and poultry to capture the possible impacts from these predictors, with the hypothesis that these variables affect farmers' application of organic fertilizer.

As shown in Table 8, through the predictor selection method of Backward, six variables are included in the final model. Judging from the odds ratio of each variable, (1) farms from the north (north=1) are less probably to use organic fertilizer. Further investigations are necessary to explore the possible reasons in planting structure, habits, and awareness on the function of organic fertilizer. (2) Age of farm head is positive with farmyard application. It may be interpreted as that with the accumulation of social experiences, farmers are more confident about the effectiveness of organic fertilizer, or the significance of properly disposing the feces and urine. (3) Similar with the findings of X. Zheng (2010), annual cash incomes is positive with farmyard application as well. With the increase of income, farmers need cleaner environment and safer food supply, thus they are apt to fertilize their farmland with organic fertilizer, rather than chemical fertilizer (as analyzed above). (4) Farms with larger sowing scales are less prone to use organic fertilizer, probably due to the fact that they are pursuing higher productive efficiency and tend to use chemical fertilizer. In addition, the collection and application of organic fertilizer enough for their large sowing scales is consuming in labor and funds. (5) Sowing ratio of grain crops (grainr) is negative with the application of organic fertilizer, which can be interpreted as most of the grains are sold out while the economic agro-products will be consumed by the farmers themselves. Hence they are tending to fertilize the economic crops with organic fertilizer with are labor-consuming but deemed as salubrious by the farmers (C. Yin, et al., 2010). (6) Income ratio of migrant job (mir) is found negative with the application of organic fertilizer. The main reason behind may be the fact that, farms lying on more the non-agricultural income usually have less time and attention to farming, much less fertilizing their farmland through organic fertilizer. Meanwhile, no significant relationships are detected between the application of organic fertilizer and chemical fertilizer (similar with X. Zheng 2010), breeding of livestock and poultry. It indicates the existence of blindness in application of organic fertilizer, which may bring about improper disposal of manure and compost, thus environmental pollutions.

\section{CONCLUSIONS AND RECOMMENDATIONS}

\section{Major conclusions}

Based on a survey to 560household farms in 6eastern provincial-level regions of China, this study explores farmers' behaviors, perceptions and determinants of fertilizer application. The behaviors involve total amount of chemical fertilizer and the use of organic fertilizer; farmers' perceptions are ranging from choosing and field application, the consequences of over fertilization and disposal of the used packages. Logistic regression models are used to identify the significant determinants of their behaviors.

The survey shows that most farms are using Nitrogen fertilizers, while Potash fertilizers are used in few farms. Comparing with the other plants, less chemical fertilizer are used in the main grain crops of wheat, corn and rice. Judging from the Fertilization Coefficient, more than 60percent of farms are using fertilizer with

Table 8. Binary logistic regression on application of organic fertilizer

\begin{tabular}{lcccccc}
\hline & B & S. E. & Wald & df & Sig. & odds ratio \\
\hline North or south of China (north) & $-1.265^{* * *}$ & 0.484 & 6.820 & 1 & 0.009 & 0.282 \\
Age of farm head (age) & $0.029^{*}$ & 0.016 & 3.192 & 1 & 0.074 & 1.029 \\
Total cash income in 2010 (income) & $0.574^{* * *}$ & 0.217 & 6.974 & 1 & 0.008 & 1.775 \\
Sowing area (scale) & $-0.123^{* * *}$ & 0.037 & 11.301 & 1 & 0.001 & 0.884 \\
Sowing ratio of grain crops (grainr) & $-0.010^{* *}$ & 0.005 & 4.218 & 1 & 0.040 & 0.991 \\
Income ratio of migrant job (mir) & $-0.026^{* * *}$ & 0.005 & 25.254 & 1 & 0.000 & 0.975
\end{tabular}

Cases included in analysis: 267; Missing cases: 33; Total cases selected: 300

Dependent variable: whether organic fertilizer is used, with 178 cases $=1$, and 89 cases $=0$

Omnibus tests of model coefficients: Chi-square (6) $=86.382$, Sig. $=0.000^{* * * *}$

Note: ***,**and *represent statistical significance in the level of $1 \%, 5 \%$ and $10 \%$, respectively.

Software: SPSS 13.0 
amounts no more than 50percent deviating the average amounts with certain fertilizing regions.

Perceptions of proper fertilization are held by some farmers, including applying fertilizer by instructions, recycling the packages collectively, concerning on the possible crop lodging and soil compaction due to over fertilization. Simultaneously, traditional conceptions still affect many farmers, such as the over emphasized productive effects and private experiences, reusing the packages for food-storage, etc.

According to the empirical analyses, sowing area and ratio of migrant income is positive, while annual income is negative for appropriate fertilization. As to the odds of using organic fertilizer, no significant effects detected from chemical fertilizer application and breeding of livestock and poultry, while cash income and age of householders are positive, location in the north, sowing scale, ratio of grain crops and migrant income are measured as negative.

\section{Policy recommendations}

(1) As shown above, the fertilizing elements are not well balanced, and amounts of fertilizer used in many farms deviate much from the moderate levels. Therefore, it is an urgent task for the government to provide prompt, accurate and convenient soil testing techniques, and recommend referential standardized fertilizing amounts to farms with different land properties and planting structures (F. Zhang, et al., 2008).

(2) Enlarging the managerial scales of agriculture. As analyzed above, larger scale is positive to maintain appropriate fertilizing amounts. Managerial scales of the farms can be expanded either through the concentration of land on farms' own willing, or joining into the Specialized Farmers' Cooperatives as demonstrated by Q. Sun (2008), H. Dai (2010).

(3) Promoting migrant employment of rural labors, as ratio of migrant income is positive to appropriate use of fertilization and application of organic fertilizer. To accelerating the transfer of surplus labors from agriculture to the other sectors, thus increase incomes of rural households, the main tasks include promoting the vocational training, perfecting the employment information networks, and protecting the legal rights of the migrant workers.

(4) Strengthening social education on scientific fertilization. This survey reveals that behaviors including fertilizing by private practices, misusing the used packages, etc, still exist amongst many farmers, and their perceptions on safe application of fertilizer need to be improved. Hence educations on appropriate amounts of fertilizer, balancing the elements, proper recycling the used packages, etc., are in high necessary of to be strengthened (C. Yin, et al., 2010).

\section{Open research topics}

In farms' use of fertilizer, there are still some points open for further studies, e.g., reasons behind impacts of the farms' location in the north or south, gender of the householders, etc. In future researches, inclusion of these contents in the questionnaire, will benefit further interpretations. Moreover, additional questions can be included, such as the determinants out of the farms like the price changes of fertilizer, motivation for using organic fertilizer, etc., hence are referential for policy recommending.

\section{REFERENCES}

B. Yan 2010 Investigation on the training effects of precise and quantitative fertilization in rice towards farmers' perceptions and behaviors in Pizhou County, Jiangsu Province, Chinese Journal of Economic Research Guide, 7: 38-39

Bruin J. 2006 Newtest: Command To Compute New Test. UCLA Academic Technology Services, Statistical Consulting Group. http://www.ats.ucla.edu/stat/stata/ado/analysis/

C. Yin, P. Wu and Y. Zhang 2010 Research on farmers' will to reduce the amount of crop fertilizer. Chinese Journal of Jiangsu Agricultural Sciences, 1: 384-387

CNSB (China National Statistic Bureau). The annual data of irrigated area, consumption of chemical fertilizer and rural hydropower stations and electricity, http://www.stats.gov.cn/ tjsj/ndsj/2010/html/M1306e.htm

D. Li, Teruaki Nanseki, Kazuhiko Hotta and Shoji Shinkai 2011 A Factor Analysis of Chinese Agricultural Development Using Production Function: The Inputs Change and Technological Progress, 1983-2006, Japanese Journal of Food, Agricultural and Resources Economics, 61(2): 1-10

F. Zhang, J. Wang and W. Zhang 2008 Nutrient use efficiencies of major cereal crops in China and measures for improvement. Chinese Journal of Soil Sciences, 45(9): 915-924

H. Dai 2010 The impact analysis of agro-chain to farmer's safe production behavior, Chinese Journal of Hubei University of Economics, 8(4): 73-78

H. Gao, Z. Liang and X. Chen 2011 Analysis of factors influencing adaptation of the technology of formula fertilization by soil testing: based on the questionnaire survey of farmer households in Fujian Province, Chinese Journal of Fujian Agriculture and Forestry University (Philosophy and Social Sciences Edition), 14(1): 52-56

H. Han and L. Zhao 2009 Farmers' character and behavior of fertilizer application: evidence from a survey of Xinxiang County, Henan Province, China, Journal of Agricultural Sciences in China, 8(10): 1238-1245

H. R. Seddighi, K. A. Lawler and A. V. Katos 2000 Econometric: A Practical Approach. Routledge Press, London, pp.105-106

H. Wang and X. Xu 2004 Micro behaviors and the safety of agroproducts: an analysis of rural production and resident consumption, Chinese Journal of Nanjing Agricultural University (Social Sciences Edition), 4(1): 23-28

J. Ma 2006 Analysis on amounts and determinants of fertilizer applied on cereal crops by the farmers: a case study of North China Plain, Chinese Journal of Agricultural and Technological Economics, 6: 36-42

J. Y. Lin 1992 Rural Reforms and Agricultural Growth in China, the American Economic Review, 82(1): 34-51

J. Zhang and R. Li 2007 Rural environmental pollution and the countermeasures for sustainable development, Chinese Journal of Anhui Agricultural Sciences, 35(15): 4588-4617

Jack J. and John D 1997 Econometric Methods (Fourth Edition). The McGraw-Hill Companies, Inc., New York, pp.415-418

K. Deininger and G. Feder 2001 Land Institutions and Land Markets, Handbook of Agricultural Economics, Volume 1A, Edited by B. Gardner and G. Rausser, Elsevier/North-Holland Press, p. 289

Q. Gong, J. Zhang and J. Li 2008 Analysis of factors affecting farmers' decision-making on fertilizer application, Chinese Journal of Agricultural Issues, 10: 63-68

Q. Gong, J. X, Mu and Z. Tian 2010 Factor analysis on Farmers' risk perceptions and the avoiding abilities on excessive 
fertilization, Chinese Journal of Rural Economy, 10: 66-76

Q. Song, J. Fang and Y. Li 2010 Discussion on Influencing Factors of Farming Household's Safety Agricultural Products Production, Chinese Journal of Chinese Agricultural Science Bulletin, 26(24): 466-471

Q. Sun 2008 Analysis on the determinants of production of safety agricultural products by farms, Chinese Journal of Food and Nutrition in China, 1: 15-17

W. E. Huffman 2001 Human capital: education and agriculture. In "Handbook of Agricultural Economics", Vol. 1A, ed. by B. Gardner and G. Rausser, Rausser, Elsevier/North-Holland Press, pp.344-345

W. Han 2005 Survey and analysis on environmental problems in the poverty rural areas of Sichuan Province, Chinese Journal of Rural Economics, 11: 99-101

W. Zhang, A. Xu and H. Ji 2004 Estimation of agricultural nonpoint source pollution in China and the alleviating strategies
III: a review of policies and practices for agricultural non-point source pollution control in China, Chinese Journal of Agricultural Sciences, 37(7): 1026-1033

World Bank 2011 World Development Indicators Database, http:// data.worldbank.org/data-catalog

X. Zheng 2010 Analysis of the influencing factors on the farmers' use of manures in Danjiangkou reservoir area, Chinese Journal of Hunan Agricultural University (Social Sciences), 11: pp. $11-15$

Z. Liu and X. Sui 2008 Regional characteristics of fertilizer use in China, Chinese Journal of Resources Science, 30(6): 822 828

Z. Yang and H. Han 2011 Technical efficiency of fertilizer and influencing factors: Based on empirical analysis of wheat and corn, Chinese Journal of China Agricultural University, 16(1): $140-147$ 